\title{
An assessment of the energy and nutrient status of maritime security consultants
}

\author{
S. Wootton ${ }^{1}$, M. T. Mc Auley ${ }^{1}$, A. M. Coufopoulos ${ }^{2}$ and K. M. Mooney ${ }^{3}$ \\ ${ }^{1}$ Department of Health Sciences, Liverpool Hope University, Liverpool L16 9JD, UK, ${ }^{2}$ Department of Nursing \\ and Health Studies, Coventry University, CVI 5FB, UK and ${ }^{3}$ Faculty of Health and Social Care, Edge Hill University, \\ Lancashire L39 4QP, UK
}

Seafarers who possess military training, off-shore survival skills and weapon handling skills are finding alternative employment as private maritime security consultants (MSCs) ${ }^{(1)}$. MSCs often spend prolonged periods of time away from home engaging in a mentally and physically demanding role. There are no existing nutrient/dietary recommendations and no information in the literature on the nutrient intake of this group of the population. Therefore, the aim of this study was to assess the energy and nutrient intake of MSCs during deployment.

MSCs were recruited 'face to face' at their place of work before deployment. All participants were required to complete a seven day semi-quantitative food diary during the first and last week of deployment. Food diaries were analysed using Microdiet (version two; Downlee Systems Ltd, UK). Difference in self-reported weight status pre- and post-deployment was assessed in seven volunteers using a paired sample $t$ test $(p<0.05)$. Ethical approval to complete this study was granted by the Faculty of Sciences and Social Sciences Research Ethics Committee, Liverpool Hope University, UK.

Nineteen participants agreed to consent to participate in the study. Of these nineteen participants, nine returned food diaries for both the first and last week of deployment which were of a standard to proceed with nutrient analysis. The mean age of participants was 37 years. A wide variation in energy and macronutrient intake amongst participants during both the first and last week of deployment was evident. The percentage food energy derived from carbohydrate; total fat; monounsaturated fat and polyunsaturated fat did not meet UK Dietary Reference Values ${ }^{(2)}$. Mean weight status was significantly different pre- and post-deployment $(86.3 v .83 .1 \mathrm{~kg} ; p=0.012)$.

\begin{tabular}{|c|c|c|c|c|c|c|}
\hline \multirow[b]{2}{*}{ Mean Energy and Nutrient Intake } & \multicolumn{2}{|c|}{ First Week $(n=9)$} & \multirow{2}{*}{$\begin{array}{l}\text { Percentage contribution } \\
\text { to energy intake }\end{array}$} & \multicolumn{2}{|c|}{ Last Week $(n=9)$} & \multirow{2}{*}{$\begin{array}{c}\text { Percentage contribution } \\
\text { to energy intake }\end{array}$} \\
\hline & Mean & SEM & & Mean & SEM & \\
\hline Energy (kcals/d) & 3424 & 582 & - & 2745 & 485 & - \\
\hline Protein $(g / d)$ & 129 & 22 & 15 & 128 & 17 & 19 \\
\hline Carbohydrates (g/d) & 367 & 68 & 43 & 304 & 56 & 44 \\
\hline Fibre $(\mathbf{g} / \mathbf{d})$ & 12 & 2 & - & 11 & 2 & - \\
\hline Total fat $(\mathrm{g} / \mathrm{d})$ & 136 & 29 & 36 & 122 & 24 & 40 \\
\hline Saturated fat $(\mathrm{g} / \mathrm{d})$ & 27 & 4 & 7 & 24 & 4 & 8 \\
\hline Monounsaturated fat $(\mathrm{g} / \mathrm{d})$ & 24 & 2 & 6 & 24 & 3 & 8 \\
\hline Polyunsaturated fat $(\mathrm{g} / \mathrm{d})$ & 13 & 2 & 3 & 14 & 2 & 5 \\
\hline
\end{tabular}

SEM: standard error of the mean.

Macronutrient intake of MSCs during deployment was sub-optimal. These findings are important not only due to the health consequences associated with poor dietary intake, but also the impact poor diet may have on the ability of MSCs to carry out their role.

1. Department for Transport (nd) Maritime Security Guards. http://www.dft.gov.uk/mca/mcga07-home/workingatsea/mcga.healthandsafety/mcga. medicalcertandadvice (accessed March 2013).

2. Department of Health/COMA (1991) Report on Health and Social Subjects 41: Dietary reference values for food energy and nutrients for the United Kingdom. Report of the Panel on Dietary Reference Values, Committee on Medical Aspects of Food and Nutrition Policy (COMA). The Stationary Office, London. 